\title{
General Index
}

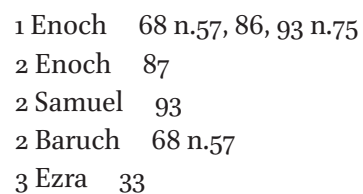

Aaron 76, 133, 141

'Abbāsid revolution 74 n.1

'Abbāsids 242

'Abd al-Jabbār 182

'Abd al-Karīm al-Jīlī 214

'Abd al-Raḥmān b. Mikhmar 111, 118

'Abd al-Wāḥid b. Zayd 109, 111, 116, 117

'Abd ibn Hamīd al-Kissī 168

'Abdallāh b. Abī l-Hudhayl 74, 82

'Abdallāh b. 'Amr 107, 232 n.90

'Abdallāh b. Rawāḥa al-Anșārī 108

'Abdallāh ibn Salām 146, 157, 16o, 161

'Abdān 244

'Abduh, Muḥammad 20

Ablutions 106, 113, 153, 154

Abode of Punishment 136

Abraham 33, 34, 128 n.9, 140, 191, 233 n.91, 242, 273

Abu l-Dardā' 109, 113, 119

Abū l-'Āliya $117 \mathrm{n} .82$

Abū l-Hasan al-Bakrī 131, 134, 135, 279, 280

Abū Bakr 110, 117, 301, 304-7, 310, 321 n.65

Abu Deeb, Kamal 147

Abū Dharr 116

Abū Hadrash 81 n.33

Abū Hanīfa al-Dīnawārī 83 n.41

Abū Hayyān 146

Abū Hurayra 108-10, 119, 125 nn.3 and 5, 169,

$$
232 \text { n.90, 276, } 277 \text { n.31 }
$$

Abū Jahl 88 n.56, $3^{21}$

Abū l-'Atāhiya, poet 80 n.25

Abū l-Faraj al-Iṣfahān̄̄ 74

Abū l-Hakam al-Jawālīqī 9o, n.66

Abū l-Layth al-Samarqandī $\quad$ 6, 271, 289

Abū l-Najm 81

Abū Maysara 107

Abū Mūsā al-Ash'arī 110

Abū Nu'aym 103, 104, 276

Abū Razīn 117 n.82
Abū Sa ${ }^{c} 1 ̄ d$ al-Khudrī 128, 129, 167, 232 n.9o

Abū Shaykh 146

Abū 'Ubayd 119

Abū 'Ubayda b. Hudhayfa 106

Adab 104, 119, 194, 196, 269

Ādam b. 'Abd al-'Azīz $\quad 74,79,94$

Adam 51, 106, 127, 128 n.9, 129, 135, 136, 140, 141, 145, 146 n.7, 229, 242, 261

Addai Sher, Chaldean Catholic

Archbishop 78 n.16

Adultery/adulterers $\quad$ 127, 281, 282, 284

Ādur 157

Afghanistan 13

Afterlife $1,7,10,11,19,20,21,30,31,32,33,35$, $92,112,120,144,178,189,194,195,199$, 200, 241, 243, 251, 256, 305

Agnosticism $117,208,223-7,228,235$ n.99

Ahl al-bayt 302-6, 317 n.6o

Aḥmad b. Hanbal $\quad$ 103, 104, 114 n.72, 125 n.3, 146, 213

al-Ahnaf b. Qays 109

Ahqāb 118, 168

Ahsan al-kibār 318, 320

Ahwwāl al-qiyāma 297, 299

al-Akwa', Ismācīl $\quad 212,214,217,218$

Albright, W.F. 6o-63

'Alī b. Fuḍayl 108

'Alī b. Muḥammad b. Abī l-Qāsim 213

'Alī 242, 269, 301-13, 317, 318, 321, 325, 327-9

Alí-de-Unzaga, Omar 282

'Ālij 209, 232 n.9o

Aljamiado literature 268-91

Aljamiado Spanish $\quad 273$

Allah (see also God) 66 n.47, 68, 70, 158

Allegories 10, 183, 242, 323 n.66

al-A'mash 90

al-Āmir, Fāṭimid caliph-Imam $\quad 260$ n.65

'Āmir b. 'Abd (al-)Qays 107

'Amr b. Shurahbīl 112

'Amr b. 'Ubayd 103 n.1

al-Andalus 131, 141

Andalusian Arabic $\quad 273,285$

Andrae, Tor $40,49,79,87$

Angel of Death $74,91,93,95,129,135$ n.28, 136 n.33 
Angelology 277, 287, 325

Angels 6, 16, 33, 6o n.20, 67, 69, 70, 74-95, $108,126-39,147-57,190,243,255,258$, 276, 286, 299, 313, 325, 326, 340-2, 344, 347,350

The Annihilation of the Fire 166

Annihilationism 8, 166-170, 175, 177, 178, 189, 208, 218-20, 246 (see also Fană’al-nār)

Antinomianism 193

Anxiety, of believers about hell $\quad 5^{-11,130-21}$ Aphrahat 38, 39, 44

Apocalypse of Paul 88-90, 156,159

Apocalypse of Peter 89, 90, 178

Apocalyptic texts/literature $\quad 93 \mathrm{n} \cdot 75,144$, 156,157

Apocatastasis $\quad 177,180,181,183,194$

Apostasy 336

Apostates 178 n.14, 241, 247, 248, 249, 259, $262,281,317$

Arab Christians $\quad 43-6,49$ n.71, 77

Arabia 43, 56, 59, 61, 83, 84, 146

Arabia, Roman Province 44

The Arabian Nights $\quad 60,64$ n.39, 144, 145

Arabic poetry 56

Arabic writings $20,79,135,139,245,268$,

269, 270-91, 297, 343

Arabic $60,61,63,77,79,82,111,146,147,158$, 182, 211, 255 n.50, 268, 277, 287, 289, 290

Arabic, Andalusian 273

Arabs $15,45,60$

al-A'rä́f 14, 33

Aramaeans 60

Aramaic 6o, 61

Ardā Virāz Nāmag 144

Arendt, Hannah 180

'Arfa 133, 137

Asad b. Mūsā 104, 105

Ascension literature 144, 156, 157

Ascension 11, 12, 35, 58 n.10, 90, 124-43, 144, 145, 157, 179, 246, 261, 278-81, 291, 297, $300,323,324$

al-A'shā 80 n.26, 159

Ash'arites $8,171,179,216,217,220,221,223$, 233 n. 94,234

al-Ashqar, 'Umar Sulaymān $\quad 20,21$

'Āshūrā' 146

Associationism 50, 139, 152, 200, 225, 228

Astrologers 247
Astronomers 247, 248

'Ațā' al-Salīmī 108

Ațfayyish, Muhammad b. Yūsuf 6

Āthāral-Muzaffar 308, 309

Atheists/atheism 18, 337, 350

'Ațiyya b. Sa'd 117 n.82

'Aț̣ār 196

Augustine 44, 177, 178, 180, 201 n.128

Autochthonous beings $\quad 56,63,69,75-84$

al-'Awāṣim wa-l-qawāṣim 212, 213, 217-21, 224-6

Awlād ḥāratinā $\quad 336,349$

al-'Ayyāshī $\quad 327$

Ayla 151

Ayyūbids 214

'Azīz-i Nasafĩ 10

Babai the Great $\quad 38-40,42,43,48$

Babylonian Talmud 77 n.11, 84 n.42

Badr, battle of $\quad 69-70$

Baghdad 112, 182 n.34, 338, 348

al-Bahrānī 6

Balkh 12

Banquets 83, 84, 88, 92

Barletta, Vincent 288

Barsanuphius $42 \mathrm{n} .38$

Barzakh 31-55, 243, 253, 257, 258, 262, 263, 264

Basra 105

al-Ba'th wa-l-nushūr 112

Bāțin 10, 242, 243, 245-8, 250, 251, 253, 256, 259

Battle, cosmic $\quad 76,77$

Battle, in hell $340,342-3$

Battles 80, 312

Battles, of Muhammad 69, 70, 269, 273, 305

Bāyazīd Basțāmī 9,183

al-Bayhaqī 125 n.3, 227

Bedouin 57

Beliar 87

Beliefs, erroneous $\quad 89,208,216,220,223,234$, $235,258,317$

Bell, R. 93

Bergson, Henri 20

Bernabe Pons, Luis 270

The Best of the Grand Men $\quad 318,320$

Bible 5, 34 n.7, 37 n.18, 86, 93

Bihāral-anwār 317 
Bilāl b. Sa'd 111

Biographies 22, 105, 211, 212, 215, 218, 308

Biographies, of Muhammad $156,160,278$

Birds 13, 81, 146

Bishops 43, 156

Blasphemers $\quad 242,284,336,349$

Blizzards $\quad 15^{8}$

Body-parts, speaking to confess sins $\quad 77$

Bohras, Indian 245

Book of Majesty 15

Book of Songs 74

Book of the Holy Hierotheos 61

Book of the Tree 244

Book of Union 39

The Book of Wellsprings $\quad 251$

Books of Divination 297, 318

Books of Omens 297, 300, 314, 315, 319, 322, 326, 327 (see also Fālnāma)

Botticelli 120

Breath of Divinity in Cursing Witchcraft and Idolatry 304, 306

Brethren of Purity 260

Bridge, in hell $12,13,113,255$ n.48, 344

al-Bukhārī 125 n.3, 212

Bulūqiyā 144-5, 16o

Burāq 126, 138

Cairo 104, 144

Caliph 104, 157, 158, 242, 301 (see also individual caliphs)

Call to prayer 310

Camels 8o, n.26, 82, 83, 130, 146, 157, 172, 173

Candás, Pablo Roza 275

Capital punishment $\quad 186$

Castigation, in hell $176,178,179,182,183$, $184,186,187,188,195,197$ (see also punishment)

Castilian 269, 283

Castille 131

Caves $81,145,146,149,152$

Chabbi, Jacqueline $\quad 58,59,60$ n.20

Chaghatay 134, 141

Chains $17,85,87,130,137,153,188$ n.6o, 256, 341

Charity 183,190

Chauvinism 21

Chelhod, Joseph 60 n.2o

Children of our alley 336
Christ 35,36

Christian Literature $\quad 156,159,272$

Christianity $4,7,14,22,61,69,87,178,180$, 181

Christianity, Eastern $\quad 181$

Christianity, in Ireland 69

Christians $11,33,43,48,50,144,149,177,180$,

181, 224, 225, 285, 286 n.64, 288, 341

Christians, Arab 44-6, 77

Christians, Aramaean 60

Christians, Persian 182

Christians, Syriac $\quad 32,37,38,43,44-5,48-50$

Chronicle of Seert 45

Clothes, of fire $137,139,15^{2}$

Coffins 149

Colby, Frederick 11, 124-43, 279

The Colloquy of Moses and God 281-3

Comic strips 161

Commentary on Evagrius $\quad 39,43$

Common people $17,246,248,255,264$

Companions of the Cave $38,40,41$

Companions of Muhammad $\quad 6,109,113,119$, 167 168, 171, 173, 232, 242, 269, 277, 304, 305 n.25, 306 n.30, 321

Companions of Muhammad, cursed by Safavids $304-7$

Companions of Muhammad, deserving of punishment $305^{-6}$

Compassion 139 n.46, 177, 183, 193, 344

Conditions of the Resurrection 297

Consensus $7,11,165,168,171,173,176$ n.3, 209-11, 221, 223, 224, 228

Constantinople $48 \mathrm{n} .65,312$

Contemplation, of death $103,113,120$

Contemplation, of hell $103,112,113$

Conversion 141, 302, 348

Corbin, Henry 260

Cosmic Intellects $\quad 260-1$

Cosmology $13,15,132,145,148,157,260-1$, $275,277,278,346$

Cosmos 12, 70, 147-9, 184, 277

Creator 172, 195

Cress 19, 343

Crucifixion 35, 154

Cuadra, Pino Valero 286

Cultural heritage, Morisco 271

Cursing 301-11, 30

Cursing, merits of $304,305,306-7$ 
Cursing, requirement to 305

Cyril of Alexandria $\quad 77$ n.11

al-Ḍaḥhāk b. Muzāḥim 75, 116, 118

Dajjāl 149

Daley, B. 48

Damā 133, 137, 138

Damnationism 165, 166, 171, 173

Daniel, prophet 146,157

Dante 144, 341, 343

Daqā̉iq al-akhbār fì dhikr al-janna wa-l-nār 6, 21, 90 n.63

David, Prophet $\quad 110,200$

Dāwūd al-Tâ̄ī 112

Day of Judgment $\quad 35,37,38,40,41,42,46,50$, $51,75,76,77,85,275,287,313,324,325$, 328,329

Day of Resurrection 15, 154, 199, 200, 253, $257,258,328$

Day of Resurrection, Aljamiado Narratives of $\quad 275^{-277}$

De Fuentes, Galmés $\quad 270,272$

De Smet, Daniel $\quad$ 10, 241-67

Dead Sea Scrolls 93 n.75

Dead, lack of awareness of time $\quad 37-42$

Dead, unconsciousness of $\quad 40-42,46,51$

Death and sleep, association of $\quad 38-46,47$

Death, Morisco concept of 271

Demise of hell, doctrine of 8 (see also annihilationism)

Demonology, pre-Islamic 59

Demons $14,16,56,60,61,79,80,82,84,88$, 92, 93, 299, 321

Devils 22 n.133, 67, 149, 153, 154, 155, 178, 242, $245,246,308,310,342,344,345$

al-Dhahabī 7, 219, 220

Dialogue with Heraclides $\quad 43,44$ n.48

Dialogue, between 'Abdallāh ibn Salām and the caliph 'Uthmān $\quad 157-8,161$

Dialogue, between al-Zahāwī and Munkar and Nakīr $\quad 340-3$

Dieu and La fin de Satan 343

Disavowers 302, 304

Disobedience 109, 144, 149, 193, 216, 221, 224, 257,281

Dissimilation 217, 218

Divination 297, 300, 301, 317, 318, 321, 330

Divine benevolence $\quad 182$
The Divine Comedy 120

Divine grace 182 n. 34, 189, 200, 221, 250

Divine Names $\quad 171,172,189,190,197$

Dogs $81,82,262$

Doubt, in religion $\quad 83,230,251,338-40,344$, $345,348,351$

Dove 282 n.50, 286

Dreams 19, 39, 41, 343, 349

Drink/drinking $17,74,83,92,94,105$ n.9, 108, 111, 114, 116, 120, 153-5, 158, 279, 280, 281, 284, 285 n.6o, 286, 321, 341

Dualists $\quad 60,177,181,241$

Dura 60 n.21

al-Durra al-fäkhira $\quad 85$

Early scriptures 119

Eating 19, 106, 111, 114, 282

Ebūssu'ūd Efendī 304 n.20

Ecclesiastes, Book of $34 \mathrm{n} .7$

Ecclesiastical History 42

Egypt $20,87,104,214,241,336$

Eilers, W. $\quad 8,78$

Elites 17, 246, 304, 305, 311, 312, 318, 329, 330

Encyclopaedia of Islam 1

Encyclopaedia of the Qur'ān $\quad 2,67$

End of the World 244

End of Time 12, 31, 76, 177, 306

Enoch 141, 144 (see also Idris)

Ephesus 39, 40, 42

Ephrem $\quad 35,38,39,41,44,47,51,79,87$

Epicurus 19, 342

Epigraphic inscriptions $\quad 310,318$

Epistle of Forgiveness 19, 343

Epistle of Unity 20

Eschatological literature, Aljamiado versions of $273-88$

Eschatological literature, Spanish Islamic, nature of $\quad 270-3$

Eschatology $1,2,6,16,19,38,46,49,176,178$, $181,183,184,193,194,213,241,242,251$, 253, 256, 264, 268-91, 297

Eschatology, Jewish 87

Eschatology, Shi'i $\quad 241-64,313-31$

Esotericism 181, 241, 252, 256, 257, 264

Eternal life 310

Ether 339, 340, 341, 346, 348, $35^{\circ}$

Ethiopic $60 \mathrm{n} .21$

Eusebius 44 
Evil, reasons for $\quad 220-7$

Exclusivism 180

Exegesis $\quad 31,93,150,151,159,171,177,273$

Exegetes (see also mufassirūn) 17, 31, 37, 67, $75,78,83,90,128,129,144,171,173$

Existence of God $\quad 213,339,340,344,349,35^{\circ}$ Exodus, Book of 59, 93

Exotericists 242

The Exploits of the Victorious $\quad 308,309$

Extreme weather, from hell 106

Eyes $14,16,84,87,137,156,198,324,340,341$

Faces $16,34,87,91,110,149,313,316,317,323$, 327,340

Faces, punishment of $17,76,83,88,91,93$, $114,120,152,153,154,156,279,341$

Fainting $\quad 9,108,113,146$

Faith 4, 7, 165, 172, 178-9, 259, 288, 301, 302, $305,307,308,310,317,318,329,330,341$, $344,345,348$

al-Falaq $\quad 151,284,285$ n.61

Fālnāma $297,312-5,319,321,322,326,327$, 328

Falsification, of Quran 306

Fanā' al-nār 8, 10, 12, 20, 21, 166, 209-10, 232 n.90

Fashā 137, 138

Fate 342

Fāṭima $305,322,324,325$

Fāṭimids 241, 244, 245 n.10, 248, 251, 255

Fatwas 241, 304 n.20, 336

Fayṣal, King 346

Fazlur Rahman 20

Fear of hell 7-9, 108-10, 112, 227, 255 (see also anxiety of hell)

Fiction 11, 337, 338, 346-51

Fifth heaven, location of Muhammad's Tour of hell $125,132,133-4,139,140,141,279$

Fire, as fragment of the fire of hell 106-8

Fire, celestial $\quad 246$

Fire, corporal $\quad 245^{-6}$

Fire, nocturnal and diurnal $\quad 5^{8-59}$

Fire, spatial $\quad 246$

Fire, the $7,9,13-7,19,33,62,68,75,83,88$, $90,103,105-16,119,126-42,154-9,165$, 168-73, 176 n.3, 18o, 187-92, 195, 197, 202, 208-35, 248, 250, 275, 276, 286, 287, $327,328,342$
Fish, and Jonah, eschatological dimension of $36-7$

Fitra $180,181,183,185,192$

Food $83,85,87,117,129,153,155,167,282,341$

Forelocks 76,77 n.11

Forgiveness 49, 128, 178, 194, 198-200, 343

Fornication 17

Fourier 191

Fruit, of zaqqūm 14, 83, 84 n.42, 149, 153-5, 321

Frutos, Alberto Montaner 272, 291

Fuḍayl b. Tyāọ 108

Furāt al-Kūfī $\quad 317,327$

Gabriel, archangel $\quad$ 126-39, 276, 279, 313, 325 (see also Jibrīl)

Garden, the $86,108,109,110,111,115,119,126$, $129,132,136,138-40,166,167,169,171-3$, 201, 231, 242, 325 n.78, 327, 328

Gates of hell $10,13,16,86,87,88,129,137,138$, $149,150,151,158,247,257,275,286,318$

Gavin, F. 44

Gehenna 13, 37, 84 n.42

Gehinnom 12, 13, 84 n.42

Geometricians 246

George, martyred monk 48

Ghayyan 150

al-Ghazālī $\quad 6$, 9, 10, 17, 18, 85, 181, 217, 223, 226, 227, 241, 242

al-Ghazwān 108 n.25

Glosses $88,114-9$

Gnostics 84,260

God (see also Allah), passim

God, as "ether" $339,340,341,346,348,35^{\circ}$

God, death of 336

God, Muhammad's audience with $\quad 125,129$, $134,135,136,138,139,140$

God, throne of $19,85,135,148,150,200,243$, $323,342,349,35^{\circ}$

Gog and Magog 341

Gold $110,114,152,308,313,318,322-5$

Goldziher, Ignaz 3

Good deeds 182, 310, 345

Good intentions 341

Gospel of Bartholomew 87

Gospels 173 (see also individual gospels)

Great Resurrection $\quad$ 243-4, 249, 251, 252, 257, 262 n.71 
Greece $\quad 141$

Grief 151, 302

Griffith, S. $\quad 42$

Grimme, H. 79,82

Gruber, Christiane $\quad 18,133,141,297-335$

Guardians of hell $\quad 85-87,93$

Guide, heavenly $139,156,157,225$

Guinan, M.D. 47

al-Hab $\quad 287$

Haddad, Yvonne $\quad 18,19$

Hades 33, 87

Hādì al-arwāh $\quad 210,219,220,232$ n.90

al-Hādī ilā al-Haqq 215

Hadith $\quad 6-8,10,11,13,17,20,21,67-8,81,85$, $103-5,108-9,117,120,125-7,131,141,146$, $151,158-60,170,177,188,210,212,214$, 224, 227, 228, 232, 247, 257-8, 271, 276, $278-81,287,288,316,317,324,325,328$

Hadna 133, 137

Hadramawt 12

Hāfiz 300

al-Hajar, Rizq $\quad 211,216,217$

Hail 160

Hair 16, 76, 91, 109 (see also forelocks)

al-Hakīm al-Tirmidhī $117,126,130,183$

al-Ḥākim, Fāṭimid caliph-Imam 255, $25^{8}$

Hakkı, İzmirli Ismail 20

al-Hallāj 342

Hamīd al-Dīn al-Kirmānī $\quad$ 10, 255-6o

Hamza, Companion of Muhammad 117 n. 82,321

Hamza, Feras $\quad 178$

Hanafī 212, 2214, 215

Hanbalī 175, 176, 180, 184, 208

Handbooks, eschatological 6

al-Hānī, Nāṣir 343

Hanīnā 133, 137

Hannād b. al-Sarī 104, 115

al-Harbī, 'Alī 211, 217, 233 n.91

Harim b. Hayyān 105, 109, 119 n.88

Hārūt and Mārūt $\quad 341$

Harvey, L.P. $\quad 289$

Hasan 310, 323, 324

al-Ḥasan al-Bașrī $\quad 8,75,103,106,108,109$, 116,118

Hawk 282 n.5o

Hawting, Gerald $\quad 43,5^{\circ}$
al-Hazan $\quad 1^{1}$

Heaven $1,5,11,13,19,51,58,67,75,82,89,92$, $116,120,124-42,144-5,156-7,166-70$, 173, 190, 200, 209, 220, 221, 228, 244, 246, 248, 250, 260, 273, 279, 297, 299-301, $305,321,322,324,327,329,340,342$

Heaven, everlasting nature of 12, 166-70, 188, 258-9, 310, 324, 329

Heinen, Anton 146

Hell, in Aljamiado literature $\quad 274-91$

Hell, cold of $14,68,106,148,155,15^{8-61}, 171$, 247

Hell, descriptions of $12-5,104,119,135$, $145,146-53,173,279,246-7,255,256$, 281-90, 313-28

Hell, duration of unknown $\quad 218-27$

Hell, on earth $12,242-43,246,248,249,251$, $252,253,255,262-64$

Hell, everlasting nature of $12,19,154,165^{-73}$, 175-205, 208-28, 230 n.79, 231 n.82, 233 n.92, 235 n.97, 249, 254, 258-59

Hell, fear of $\quad 7-9,103-21,181,227,255$

Hell, geographication of $150-1$

Hell, guardians of $16,85^{-87}, 90,93,124-28$, $133-38,148,155,15^{8}$

Hell, heat of $13,14,17,62,65,68,106,110,114$, $116,148,155,158-61,190,247$

Hell, legal function of 187-94

Hell, located in planetary spheres $\quad 246-50$, 251

Hell, location of $\quad 62-65,67,124-42,147$, 246-50

Hell, as a monster $\quad 85-87,93$

Hell, Moses' tour of $\quad 144,159,225,234$ n.95

Hell, Muhammad's tour/vision of 122-42, 278-81

Hell, place of healing $\quad 170,185,186,187$ n.56, 192, 194, 195

Hell, in popular imagination $\quad 15,144-61$, 274-91

Hell, purpose of $\quad 224-7$

Hell, reason for existence of 157

Hell, reminders of $\quad 9,103-21$

Hell, seven gates/levels/layers of $10,13,14$, 17,110 n. $43,133^{-} 38,144,148-54,245^{-50}$, 275, 284-86, 318

Hell, spiritual nature of $10,20,242-43,246$, $249,250,252-53,257,258,260$ 
Hell, temporary nature of $\quad 7,9,14,167-70$, $175^{-205}, 219-23,248-250$

Hell, wind of $63,81,160,342$

Hellfire 9, 17, 106, 124-32, 135, 136, 138, 140, $141,179,183,188,191,208-28,242-7,251$, $299,307,317,328,329$

Henana of Adiabene 42

Henninger, Joseph $\quad 61,63,65,66,81$

Herat 141

Heresiographers 45,176

Heresy $\quad 43-5,171,172,182,337-9,349$

Heretics 44, 167, 171, 177, 208, 230, 241, 306 n.31, 307, 316, 317, 321, 337, 341

Hermeneutics 176, 193, 305

Hierarchies, in hell $6,17-18,56,69,70,250$, 263

Hijaz 58, 6 o n.20, 69

Hilyat al-awliyā' 103, 276

Hippolytus 36 n.16

Historiography 268

Hofmann Vannus, Iris 290

Homilies $\quad 34,35,37,39,47-9,77$ n.11, 87, 311

Hoover, Jon $\quad 8,185,208-37$

Hope 108, 114, 155, 173, 178, 179, 181, 222, 226 , 231, 232, 262

Horovitz, J. 84

Horror films 161

Horses 80, 81, 311

Hour, the $31,42,68,86,297,300,316$

Houris 84, 92, 111

House of Osman 302 (see also Ottomans)

Hudūd 185, 186, 195, 197, 199, 243

Hugo, Victor 343

Hujwīrī, Persian mystic 9

Humama, Companion 109

Human experience $344,345,35^{\circ}$

Hunayn, battle of 305

Husayn 310, 318, 321, 323, 324

al-Husayn al-Marwazī 114

al-Husayn b. al-Hasan 104

al-Husayn b. al-Walīd 263

Huțama $\quad 13,85,149,247,276,278,286$

Hymns $35,39,41,47,77,87$

Hymns on paradise 39,47

Hypocrites $18,149,259,286$ n.64, 316-8, 340

Iberia $\quad 268-70$

Iblīs $67,70,185$
Ibn 'Abbās 7, 74, 116, 117, 125, 131-6, 140, 141, 227,232 n.90, 275-9

Ibn Abī l-Dunyā ～6, 15, 104, 119, 146

Ibn Abī Shayba $\quad 85,104,115-8$

Ibn al-'Aqìl $\quad$ 18o, 181, 183, 186

Ibn 'Arabī $\quad 175^{-207}$

Ibn 'Asākir 126 n.7

Ibn Ḥajar al-'Asqalānī 214

Ibn Ḥajar al-Haythamī 7

Ibn al-Ḥajj, Muḥammad b. Muhammad 81 n.31

Ibn Ḥazm 171

Ibn Ḥibbān al-Bustī $\quad 146$

Ibn Ḥibbān 146

Ibn Hishām $\quad 65$ n.43, 90, 127-9, 132

Ibn Isḥāq 88 n.56, 127, 151, 157, 200

Ibn Kathīr 151, 159

Ibn Khayr al-Ishbīlī $\quad 105$

Ibn Mas'ūd 90, 105, 107, 116, 168, 232 n.9o

Ibn al-Mubārak 103-5, 114-9

Ibn Qayyim al-Jawziyya $\quad 20,21,165,166-70$, 171, 175-207, 208-11, 219, 220, 227, 228, 232

Ibn Qutayba 90, 104, 119

Ibn Rushd 19, 342

Ibn Sa'd 126, 130

Ibn al-Ṣalt, Ḥanūn b. Yūḥannā 182

Ibn Sīna 19, 190, 342

Ibn Sīrīn 105, 106

Ibn Taymiyya $\quad 8,166-73,175^{-7}, 184,176$ n.52, 189, 193, 208-11, 217-32, 233 n.91, 235 n.99

Ibn 'Umar 108, 109

Ibn Waththāb 91

Ibn al-Wazīr $\quad$ 8, 208-35, 212-8

Ibn Ya'mar 90

Ibn Zayd 116, 117

Ibrāhīm al-Taymī 111

Ibrāhīm b. al-Ḥusayn al-Hāàmidī $\quad 260$

Ibrahim Efendi $\quad 131-3$

Icebergs $\quad 158$

Iconoclasm $307,308,310$

Icons $307,308,313,328$

Idolaters $43,307,316$

Idolatry 200,233 n.91, 286 n.64, 304, 306

Idols $70,76,307-12,348$

Idris 139, 141 (see also Enoch)

Ignorant, in paradise 341,342 
Ihyyā' 'ulüm al-dīn 9

al-Ijāda fì al-irāda 219

'Ikrima b. 'Abdallāh 118

Ilkhanid 133, 134, 141

Images, apocalyptical $\quad 297-331$

Imām al-Qāsim b. Ibrāhīm $\quad 215$

Imam, Shici $\quad 10,242-52,255^{-6}, 310-29$

Imami Shici Islam 301, 304, 312

Incitements to evil 339

Index fingers, biting of 302

India 146, 245

Indonesian $\quad 283$

Infidels $12,13,175,180,318$

Injustice 234 n.96, 305, 339, 340, 343, 345, 347,349

Innovations 171,176 n.3, 216, 235, 317, 348

Inquisition, Spanish $\quad 271$

Insects 15,262

Intercession $7,47-50,139$ n.46, 155, 177, 179, $180,183,184,195,196,199,276,277,325-30$

Intercourse, anal 154

"Intermediate state" $\quad 31-55$

Intestines 110, 16

Iqbal, Muhammad 20

Iran 297-335

Iranian literature 144,156

Iraq $19,104,181,338$

Isaac of Nineveh $\quad 181,182$

Isaiah, Book of $77,86,93$

Islamic history $\quad 69,124,131,132,142,310,336$, 337

Islamic Studies $\quad 1-4,69$

Islands, in hell 147,149

Ismāìil I, Shāh 301-4, 308, 310, 312, 323

Ismā̄il II, Shāh 304

Isma'il, angel $128,135,136$

Isma'ilis/Ismā'iliyya $\quad 10,85$ n.46, 113 n.16, 181, $215,241-67$

Isnāds 116, 117, 146, 276, 277

Isra $\bar{a}^{\prime}$ (see also Night journey) 124, 140, 278-81

Israelites $\quad 76$

Isrāfill, angel $\quad 325,326$

Istanbul 131, 133, 136, 297, 338, 339

İthāral-ḥaqq 'alä al-khalq 213, 218-21, 223, 226, 227, 229-35

Jābir 'Abdallāh Anșārī 321

Jābir ibn 'Abd Allāh $\quad 167$
Jacob of Serugh $\quad 35,38,47$

Jacob, G. 84

Ja'far al-Ṣādiq 260, 314, 315, 319, 322, 326, 327

Ja'far b. Manșūr al-Yaman $\quad 250$

Jafar, Companion of Muhammad 321, 323 n. 66

Jahīm 5, 13, 14, 145, 149, 247, 276, 278, 286

al-Jāḥiz $\quad$ 104, 118

Jahm ibn Șafwān 166, 183 n.38

Jāmi'al-șahịh 126

Jebel esh-Shāer 60 n.21

Jeremiah, Book of 5

Jerome $\quad 178$

Jerusalem 12, 125, 126, 136, 138-40

Jesus and the Skull 283-6, 290, 291

Jesus $35,87,128$ n.9, 140, 196 n.112, 233 n.91, $242,273,283-6,287,290,291$

Jesus, and the "hell monster" 87

Jews $144,146,149,157,168,169,180,224,225$, $275,285,287$

Jibrīl (see also Gabriel) $\quad 157$

Jihäd 108, 181 n.31

Jinn $6,56-73,93,119,144,147,167,229,340$

Jinn, Aramaic-Christian $\quad 60-61$

Jinn, association with Iblīs 67

Jinn, characteristics of $\quad 5^{8-65}, 66,67,69,81$

Jinn, origin of the idea of $\quad 60-65$

Jinn, pre-Islamic Arabian beliefs about 66

Jinn, translation of the image of $\quad 5^{8-72}$

Job $\quad 40,196$

John of Damascus 45

Jonah $36,37,196-8$

Jordan $\quad 21,44$

Joshua, Book of 5

Judaism 93, 110, 18o, 190 n.69, 200 n.126

Judeo-Christian tradition $\quad 68,77,86,87$

Judges $18,118,154,157,178$ n.14, 180, 181, 189, 208, 229-5

Judgment $\quad 33,35,37,38,40-2,46,47,50,5^{1}$, $62,68,75^{-7}, 79,83,85,89,104,112,113$, $119,129,156-8,170,253,275,287,297$, $300,301,304,311,313-7,321-31,343-5$, 350,351

Judgment, injustice of $343,345,347,349$

Jupiter 247, 251

Justice $\quad 172,178,187,194,196,200,223,229$

n. 75,233 n.93, 234-5, 263, 325, 340-5

Justice, model of $\quad 187-94$ 
al-Karakī, 'Alī 'Abd al-'Alī $\quad 304-8,312$

Kitābal-Aghān̄̄ 74

Kitāb al-Așnām $\quad 81 \mathrm{n} .28$

Kitāb al-'Azama 15, 144-162

Ka`b al-Aḥbār $\quad 110,275,276,278$

Ka'ba $308-10$

Kabäirir 7, 152, 219 n.47, 286 n.64

Kalām 176, 177, 208, 212, 213, 216, 217, 224, $225,228,233-5,247$

al-Kawsar/al-Kawthar $\quad 151,284,328$

Kermani, Navid 5

al-Khalada 137,138

Khalil, Mohammad Hassan $\quad 8,1^{6} 5^{-74}$

Khān, Șiddīq Ḥasan 6,165

al-Khansā' 79-81, 119

Khārijites $\quad 8,179$

al-Khargūshī 104

Khawfa 133, 137

Khazana 16, 67, 85-8, 90, 93

Khiḍr 225-7, 235

Khomeini, Ayatollah 336

Khurāsān 244

Khusr 150

al-Khuțab wa-l-mawāiz 119

Kindness, of God 9

Kings, position of in hell 158

al-Kisāī 117 n.82, 149, 150, 277

Kitāb al Zuhd 103-5, 114-19

Kitābal-Haft 260

Kitāb al-ĪỊạh 244

Kitāb al-Iftikhār $\quad 254$

Kitāb al-Mahṣūl 244

Kitāb al-Mașābìh fì ithbāt al-imāma 255

Kitāb al-Shajara $\quad$ 244-50, 251

Kitāb al-Tawahhum 113

Kitāb al-Yanābì $\quad 251,254$

Kitāb Kanzal-walad 260

Kitāb Rāhatal-'aql 255, 256

Knowledge of God, human disposition towards 192

Kontzi, Reinhold $\quad 278,279$

Kuwait 21

\section{Lāmiyyat al-'arab 57}

Last Judgement $\quad 47,104,112,113,119,297$, $300-4,313-7,321-31$

Last Judgement, fear of $\quad 112,158$
Late Antiquity $\quad 5,32-4,46,48,49,62-4,77$, 87,93

Late Middle Period 11, 133

Latin 134, 179, 185 n.64, 290 n.83

Laughter $108,110,111,119,127,128$

Law $111,147,180,184,185,187,190,193,194$, 196, 197, 199, 201, 242, 247, 248, 251, 252, 256,264

Laẓā 13, 149, 247, 276, 278, 286

Leo III, Byzantine Emperor 268

Letter to Publius 87 n.51

Letter, from Shāh Ṭahmāsp to Süleimān I $302-4$

Letter, of 'Umar II $\quad 268$

Levi della Vida, Giorgio $\quad 59,61$

Lex talionis 196

Liber Scalae Machometi $\quad$ 134, 144

Life after death 20

Light, divine, in Shi' ism $\quad 261-3,323-4$

Limbo 14

Lips $16,17,130,157$

Literary authors 336

Literature, Aljamiado $\quad 268-74,281,288,289$

Literature, Aljamiado, Arabic/Islamic basis of $272,274,277-9,280,283,284,287-8$, 289,291

Literature, Aljamiado, re-modeling in $\quad 276$, 280, 282, 283, 289

Literature, and religion $\quad 336-8$

Literature, Arabic $\quad 79,269,272,274,282,285$, 291, 343

Literature, Christian $\quad$ 156, 159, 272

Literature, Iranian $\quad 144,156$

Literature, Judeo-Christian $\quad 77,86$

Literature, Muslim $\quad$ 269, 273, 281, 283, 289

Literature, popular religious $\quad 11,144-61,269$, 275, 276, 279

Literature, Qarmatian $\quad 244$

Literature, Renunciant $\quad$ 103-21

Literature, Spanish Morisco $\quad 11$

Literature, Syriac $\quad 36,79$

Lote Tree 126, 127, 130, 323

Luke, Gospel of $\quad 33,39$

Lüling, G. $\quad 77,78$

al-Ma'arrī 19, 20, 144, 341-3

al-Mabdả wa-l-ma'ād 10

Macdonald, John 6 
Mahdī, the $\quad 323,325,328$

al-Mahdī, caliph $\quad 74$

Maḥfūz, Nagīb $\quad 336,337,349$

al-Majlisī 317, 324, 325, 327, 328

al-Makkī, Abū Țālib 8

Mālik b. Dīnār 109

Mālik 16, 90, 94, 125, 127-41, 148, 153, 155, 158, $160,275,276,287$

Mālik, as guardian of hell $\quad 133-40$

Mālik, enthroned 131

Mālikīs 212

Mamluks 214

Mandaeans 84

Manichaeans 84 n.42, 241

Manuscripts $6,16,105,133-5,138,146,147$, 242, 244, 245, 269-73, 275-7, 279, 283, 286, 290, 297, 300, 302, 308, 310, 312, 318, 321

Maqām 126

Mar Ishai 49

Mark, Gospel of 173

Market inspectors 18

Markets $18,103,109,302,308$

Mars 141, 247, 251

Martínez de Castilla Muñoz, N. 290

Martyrs $\quad 46-51,191$

al-Mas'ū ūī 81

Mathematicians 246, 248

Matthew, Gospel of 4

al-Māturīdī 117

Māturīīis 8, 179

al-Maynaqī 244

Mazdeans 285, 286 n.64

Mecca 8, 43, 104, 108, 138, 172, 209, 212, 214, 215, 218, 228, 279, 308

Meccan Period 5, 69, 92, 93

Medinan Period 69, 92, 93

Meier, Fritz $\quad 2,3,61,81$

Melchert, Christopher $\quad$ 8, 103-123

Mercury 246, 247

Mercy $3-5,8,49,50,89,110,115,120,133,152$, 169, 170, 172, 177-95, 201, 210, 221, 222, 226, 229 n.75, 230 n.78, 232 n. 87,233 , 235 n.97, 263, 325

Mesopotamia 85 n. 46

Messenger of God 126, 127, 308 (see also Muhạmmad)

Metaphysics $\quad 20,184,247,248$
Metempsychosis 10, 45, 243, 249, 255 n.48, 261 (see also transmigration of the soul)

Michael, archangel $\quad 89,126,325,326$

Michele Membré 311, 312

Middle East $\quad 31,34,43$

Middle Period $\quad 11,128,131,132,133,140,141$

Millenarianism $300,324,330$

Minbar 111, 302

Mírāj 11, 16, 90, 124-31, 135, 136, 140, 179, 278 (see also Ascension)

Mírājnāma 134, 279, 298

Miscellanies 271, 272, 275, 290

Modernity $\quad 18-22$

Money 200, 280, 282, 312

Monotheism 6, 16, 43, 50, 69, 140, 179, 180, 213, 308

Moon 246

Moriscos 11, 269-96

Moriscos, and Christians $\quad 272$

Mortality of the soul $\quad 41-46$

Moses 59, 6o n.20, 63, 76, 110, 130, 140, 144, 157 n.6o, 159, 168, 225-7, 234, 242, 273, 281-3

Mosques 17, 103, 105, 111, 116, 118, 301, 302, 308,311

Mount of Olives $\quad 12,87$

Mountain of Qāf 341, 344

Mountain 14, 133, 137, 145, 147, 149, 150, 151, $160,341,342,344$

Mouths 16, 86, 88, 127, 130, 137, 149, 153, 157, 160,302 n.14, 318

Mu'āwiya, caliph $\quad 74,80,304$ n.20, 321

al-Mu'ayyad 338

al-Mubarrad 82

al-Mufaḍḍal al-Ju'fī 260

$\begin{array}{ll}\text { Mufassirūn (see also exegetes) } & 31,32,37\end{array}$

Mufti 338

Muhammad b. Ka'b 90

Muhammad b. Wāsic 110

Muḥammad, Prophet $\quad 11,12,43,49,66$ n.47, $76,77,79,118,124-42,144,145,156,157$, 172, 184, 200, 242, 243, 244 n.8, 269, 273, 276, 278-81, 288, 297, 305, 306 n.30, 308, $309,310,313,318,321,323,324-8$, 337, 340 (see also Prophet)

al-Muhạāsibī 112, 113

Muhl 105, 116, 117, 153 
Mujāhid $\quad 64,75,116,118$

Munājāt Mūsāa 281-3

Munkar and Nakīr $\quad 340,344,347,348,35^{\circ}$

Muqātil ibn Sulaymān $\quad 86,90,151,159$

al-Muqtataf 338

Murji'is 179,180

Murra 80

Muruwwa 57

Musa Iznīkī 139

al-Mușannaf 104, 115, 196

Mushrikūn 43, 50 (see also Associationism and shirk)

Mușïbat-nāme 196

Muslim sinners $\quad 7,8,12,14,149,175,177,179$, $187,188,213,222,224,230$ n.79, 275-6, 277,286 n.64, 316

Muslim, tradition-compiler $\quad 105,125$ n.3, 201, 212

Muslims, temporary punishment for 7,14 , 112, 179, 213, $231 \mathrm{n} .82,276$

Muțarrif b. al-Shikhkhīr 108, 114

Mu'tazilites 8, 20, 165, 179, 191, 200 n.124, 208, 212, 213, 215-7, 221-5, 228, 230 n.79, $233-5,348$

al-Muzanī, Bakr b. 'Abdallāh 110

Mystics 9, 10, 61, 181, 183, 184, 186, 321 n.65, 339,350

al-Nābigha $\quad 80$

Nafīs al-Dīn al-'Alawī 212

Nafs 9, 45, 46, 201, 253

Nakedness, of sinners in hell $17,161,258$

al-Nakha'ì 108, 117 n.82

Narsai, Church Father $\quad 34-6,38,39,48$

al-Nasafī 178,185 n.47, 244

al-Nāshi' al-Akbar, Mu'tazilite theologian $182 n \cdot 36$

al-Nawawī $188 \mathrm{n} .6 \mathrm{o}$

al-Nāzighāt 339

Nafahāat al-lāhūt fì la'n al-jibt wa'l-țāghūt 304

Near East $\quad 75,91,268$

Neoplatonism 10, 180 n.24, 187 n.56, 246 n.17

Neuwirth, Angelika $\quad 57,58,67,69,84$

New Testament 48

Night Journey 124-5, 278-81, 291 (see also $\left.i s r \bar{a}^{\prime}\right)$

Nimr, Fāris 338
Nishapur 129

Nisibene Hymns $\quad 41,87$

Niẓām 308, 309

Niẓarīs 241, 244, 245

Noah 139, 198 n.120, 242

Nöldeke, T. $\quad 59,92$

North Africa $\quad 269$

O'Meara, Simon $\quad 6,5^{6-73}$

O'Shaughnessy, Thomas 5

Occult 6o, 300

Occultation 242, 243

Oceans of Lights 317

Oceans 14, 106, 116

Oral transmission $140,141,307,310$

Origen $\quad 43-5,49$ n.71, 177

Origenism 42, 43, 182

Orphans 127, 130, 156, 157, 279, 280, 282, 284, 329

Orsi, Robert 3

Ottoman Empire 338

Ottomans 297, 300, 302, 304, 312, 330, 339

Oven, as reminder of hell $\quad 108$

Pagani, Samuela $\quad$ 9, 175-207

Pahlavi 78,156

Paintings 18, 297, 300, 301, 302, 308, 310, 312, $313,316-8,321,323-6,329-31$

Paintings, as communication of ideology $311-31$

Paintings, of hell $\quad 297-331$

Paintings, Safavid $\quad 297-331$

Palestine 65

Palmyra 60 n.21

Pantheism 339, 348

Parable of the rich man and the poor man 33-4, 39

Paradise $1-17,20,21,33,39,47,52,84,92$, $108,109,113-5,125,126,128,130,144-51$, $158,167,168,173,179,180,188-94,199$, 200, 202, 213, 222, 224, 228, 241-3, 245, 250-62, 275-9, 282, 317, 318, 321, 323, $324,328,329,341,342,346$

Paraphrases 116, 117

Parenetic works $146,148,287$

Paret, R. 82, 90

Paul, apostle $\quad 18,88$

Penance 177 
People of the Fire $111,137,168,170,173,187$, 188, 192, 209, 224 (see also ahl al-nār)

People of the Garden $\quad 111,173$

Perdition 87, 150, 251, 317

Perfume market 109

Perjurers 284

Persia 131, 241 (see also Iran)

Persia, Shicification of $302,305,307,310,330$

Persian 12, 78, 79, 133, 134-6, 138, 159 252, $297,300,302,305,308,312,318$

Pharaoh 130, 172, 201

Philology 119, 268

Philosophers 10, 19, 20, 183, 241, 242, 246, 247, 286 n.64, 341, 342, 346, 347

Philosophy $\quad 10-11,176,181,341,346$

Pits, of hell 149, 153, 154, 222

Plato $178,180,187$ n. 56,342

Poetry 41, 56, 212, 338, 339, 343, 347, $35^{\circ}$

Poetry, erotic 191

Poetry, pre-Islamic $\quad 57,58,79,84$

Poets $19,34,47,48,57,74,79,80,81,94,119$, 159, 337, 340-51

Polemics $\quad 4,42-3,45,50,75,178,180,241,271$, 285 n. 64,286

Policemen 18,78

Polytheists 181 n.31, 257, 307, 308

Popular preachers 90, 118, 311, 312

Prayers $17,47,48,76,103,107,108,109$, $112-4,126,127,132,140,152-4,158,273$, 277,310

Predestination 116, 345

Pre-Islamic Period $\quad$ 56, 6o, 62, 63, 65, 69, 139 Prophet, The $6,7,11,12,18,56,66$ n.46, $79,81,85,90,106,107,111,113,116,117$, $118,125-35,144,146,157,159,160,167$, 168, 170-3, 177, 179, 183, 197 n.115, 199, 200, 224, 232, 242, 247, 250, 255, 269, 275-81, 287, 291, 297, 300, 304-6, 308, 310, 313, 318, 321, 323-5, 337 (see also Muhammad)

Prophets 33, 119, 126, 139, 145, 147, 198 n.117, 224, 242, 247, 261, 263, 269, 273, 275, 277 (see also individual prophets)

Providentialism 185

Psalms of Solomon, Book of 34 n.7

Psalms, Book of 200

Public squares 301,312

Punisher-angels $\quad 6,16,91,93,126,139,286$
Punishment in hell, eternal nature of 12,19 , 154, 165-73, 175-205, 208-28, 230 n.79, 231 n. 82,233 n.92, 235 n.97, 249, 254, $25^{8-} 59$

Punishment $\quad 3,5,7-9,10,12,14,16-18,20,31$, $33,37-39,75,76,88-91,93,111,112,120$, $124,125,127,129-43,148,15^{2-56}, 159$, 169, 171, 175-80, 185-202, 210, 211, 213, 221, 223-25, 228, 243, 242-64, 277, 279, $282,285,287,298,301,302,304,305$, $307,316,329,342-47$

Punishment, al-Zahāwīs dream of 341

Punishment, as medical treatment 170,185 , 186, 187 n.56, 192, 194, 195

Punishment, of Muslims 7, 14, 112, 129, 131, 153, 179, 213, 224, $231 \mathrm{n} .82,276,316$

Punishment, of non-Muslims $\quad 131,172,175$, $305,306,313,316,317,318,329$

Punishment, reasons for $\quad$ 193-201

Punishment, temporary $7,9,14,167-70$, $175^{-205}, 248-250$

Punishments, of sinners $\quad 15-8,74-7,83$, $84,89,91,124,132,135,137-8,139,148$, $15^{2-7}, 159,246-8,258,259,263,279-80$, $281-2,287,297,313-6,318-21$

Purgatory 7, 14, 84 n.46, 112, 120, 179, 248, 250,251

Purification $170,172,186,194,195,248,252$

Qadarites 18

al-Qāḍī, 'Abd al-Rahịim $\quad 6$

Qäim 243, 244 n.8, 246, 249, 250, 252-4, $256-9,261263,264,325,328$

al-Qārī al-Harawī 8

Qarmatians 241, 244, 245 n.10, 248, 251

Qāsim ibn 'Alī, painter 318

Qatāda b. Di'āma $\quad 75,118$

Qatlā l-Qur'ān 119

Qisas al-anbiy $\bar{a} \quad$ 149, 277

Qiyāma 243, 252, 253-4, 256, 258 (see also Resurrection)

al-Qummī, 'Alī b. Ibrāhīm 128-30

Qumran 34 n.7

Quran, and Late Antique (Christian)

ideas $47-51,62,64,77,79,86-87$,

91, 93

Quran, burned by 'Uthmān 306

Quran, Falsification of 306 
Quran, passim

Quranic commentary $103,115,116,119,121$, $128,168,146,150,159,160$

Quraysh 88 n.56, 138 n.39, 307

Qurratal-'uyūn 6,7

al-Qurțubī 6, 13, 21, 85, 159, 188 n.6o, 200

Quṣṣāṣ 118, 144, 160

Rabbi Raziel/Eleazar 79 n.16

Rabbinic Law 196 n.112

Rabbinic Literature 93 n.75

al-Rabī' b. Khuthaym 90,113

Rābi‘a al-'Adawiyya $\quad 189$

Rain 114, 120, 160

Ramka 133, 137

Rasā’il Ikhwān al-Ṣafā' $\quad 260$

Rashīd Riḍ̄ā 20, 165, 213 n.21, 347

Rasūlids 212, 214

Rationalists/rationalism 19, 20, 339, 348

Raven, Wim 15, 144-62

al-Rāzī, Fakhr al-Dīn $\quad 6,223$ n.58

Rebirth 10, 243, 252, 256

Reciters of the Quran 120, $15^{2}$

Refoulé, F. $\quad 44,49$ n.71

Regrets, over sins $\quad 89,108,258$

Reincarnation $\quad 248,250,252,261$ (see also metempsychosis and transmigration of the soul)

Religion, and literature $\quad 336-8$

Religion, and science $\quad 338,339$

Religious authorities $\quad 215,228,336,337,349$, 350 (see also 'ulamā')

Renunciants 8-9, 103-21

Repellers (see also zabāniya) 16, 82-84, 88, 91-3

Repentance $7,8,32,37,51,52,89,144,213$, 230 n.79, 261, 281, 348

Resurrection $5,10,15,17,31-44,47,51,5^{2}$, 112, 241, 243-5, 249, 251-6o, 275-7, 297, 299, 300 (see also Day of Resurrection and Qiyāma)

Retribution $37,46,127,156,178-9,184,187$, 196-8, 225, 228, 305, 316

Reuter, William $\quad 278-80,289$ n.79

Revelation $8,59,66,67,93,176,192-4,201$, $215,221,222,231,242,243,248,256,260$, 313,337

Revolution in hell $\quad 336-51$
Rewards $5,14,20,31,38,39,47,48,51,5^{2}$, $168,170,177,186,188,189,194,196,197$. 232, 242, 243, 245, 250, 254, 255, 257, 327

Reynolds, G.S. $\quad 37,3^{8}$ n.20, 49, $5^{1}$ n.73

al-Ri‘āya li-ḥuqūq Allāh 112

Riccoldo of Monte Croce 4

Rich people $33-5,173,280$

Rippin, Andrew 67

al-Risāla al-jāmi'a $\quad 260$

Risālat al-ghufrān 19,343

Risālat al-tawhīd 20

Ritual ablutions 153 (see also ablutions)

Ritual prayer $103,107,108,112,114$ (see also prayer)

Ritual purity $\quad 112-3$

Rivers 14, 146, 149, 151, 284

Rod, of Moses 59, 63

Rodriguez, Vespertino 282

Rods, as punishment tool in hell 88,112 n. $57,152,153$

Romance philology $\quad 268$

Romans, Book of 42 n.38

Rulers $17,18,153,157-8,212,214,302,304$, 317

Rulership, divine right to 302

Rūmī 10, 20

Rushdie, Salman $\quad 336,337,349$

Rykmans, Gonzague 6 o n.20

Sabians 84

Sacd b. Abī Waqqāṣ 113

Sa`d b. 'Alī al-Zanjānī 215

Sa'da, Yemen 212

Sadan, Joseph 282

Sadism 120, 161

Safavids $\quad$ 18, 297-335

al-Saffārīn̄̄ 6

Saghāir 7

Sahịh 105, 176, 201

Sa'̄ì b. 'Abd al-'Azīz 103, 112

Sa'īd b. Janāh 6

Sa`īd b. Jubayr $\quad 118$

Saints $47,177,178,182-4,348$

(al-)Sa'īr $\quad$ 13, 86, 149, 276, 278, 286

Șakhr, King of the Jinn $\quad 144,145$

Sakrān 150

Salafis $\quad 20,21,175$ n.2, 210

Saljūqs $\quad 241$ 
Salvation $\quad 3-11,51,52,177-84,208-37,243$, 249, 250 n.31, 251, 261-3, 300, 302, 305, $310,313,316,324,328,330$

Sam Mirza 312

Șan'ā’ 151, 212, 214

al-Ṣan`ānī, Muḥammad b. Ismāc̄il

al-Amīr 219

Saqar 13, 83, 145, 149, 151, 246, 286

Saqțiyāyīl, angel 133

Sarandīb 146

Sarḥāìl, angel $135,138 \mathrm{nn} .40-1$

Satan/Satans $16,22,58,111,130,172,242,245$, 246, 247

The Satanic Verses $\quad 336,349$

Saturn 247-51

Șa'ùd 151

al-Șawāiq al-mursala 210

Scepticism 61, 337-9, 345, 348-50

Scholars, in hell $17,15^{2}, 246-48,346$

Science, and religion $\quad 338,339$

Scorpions 14, 15, 130, 137, 148, 149, 152, 153, 161, 262, 281, 299, 318, 321, 341

Sea $12,32,64,106,107,147,149,168,342$

Secondary divinities $\quad 5^{0}$

Sermons $87,287,301,312$

Serpents $14,87,281,287,341$ (see also snakes)

Seven Sleepers of Ephesus 39-42

Seventh heaven $125,134-5,140,141$

Sezgin, Fuat 146

Shaddād b. Aws 107

Shafā'a 7, 50, 183, 325 (see also intercession)

Shāfiīs $208,212,214,215,218,219$

al-Shahrastānī 182, 216

Shame, of sinners $\quad 16$

al-Shanfarā 57

Sharī‘a 131, 184, 196

al-Shawkānī, Muḥammad 211, 215

Sheol $34-9,47,51,86,87$

al-Shiblī 183

Shifä'al-'alīl 210, 232 n.9o

Shi'i 4, 6, 18, 125 n.3, 128, 134, 212, 230 n.79, $241-67,300-12,317,318,321,323-5$, 327-30

Shirk 139, 200, 225, 257 (see also

Associationism)

Shoemaker, Stephen J. $\quad 268$

Shumayyil, Shiblī 338
Sifat al-nār 104, 119, 146 n.13

al-Sijistānī, Abū Ya'qūb 10, 250-5, 256, 257 , 260

Sijjīn $12,17,136$ n.33, 241, 244, 259, 26o-3

Silk 78, 110, 111, 152

Silver $105,114,147,152,308,323$

Sinners $2,7,8,12-4,16-8,32-8,40-1,46$, $50,74-7,83,85,86,89,91,93,124,132$, $135,148,149,151,155,158,159,165,177-8$, 181, 184, 187, 195, 213, 222, 250, 259, 263, $275^{-7}, 283,306,313,316-7,329,343-5$

Sinners, types of $124,125,126,148,152,156$, 246-7, 279-85, 289, 316, 318, 329

Sins $7,8,14,17,32,33,49,76-7,89,108,110$, $120,15^{2}, 156-8,170,179,188$ n.6o, 201, 210, 213, 223-5, 228, 248, 250, 253, 258, $263,316,343-5$

Sins, major 7,219 n.47, 286 n.64 (see also kabāir)

Sins, minor 7 (see also șaghāir

Sins, mortal 7

Sìra 127, 129, 308

Sirāt (the Bridge) $\quad 12,198$

Sixth heaven $125,130,134,135,136,139$

Sixth heaven, location of Muhammad's Tour of hell $135-40,141$

Skin 77, 116, 117 n.82, 118, 161, 248-9, 323

Sleep of souls, doctrine of $5,37-48$

Sleep $5,17,103,107,109,119,126,343$

Sleet 159

Smith, Jane Idleman $\quad 18,19$

Smithy, as reminder of hell 9, 107, 109

Smoke 116, 130, 132, 160

Snakes $\quad 15,59$ n.15, 64-65, 130, 137, 148, 149, 152, 153, 161, 262, 299, 318, 321, 340 (see also serpents)

Snow 159, 160

Socrates 19, 342, 346

Sodomy $17,192 \mathrm{n} .84$

Solomon $81 \mathrm{n} .31,140$

Soteriology $3,87,300$

Souls 9, 10, 79, 94, 109, 111, 129, 137, 141, 144, 156-6o, 172, 190, 192, 198, 201, 243, 246-64, 313, 340, 344

Souls, necessity of material substrate 243 , $246,25^{\circ}, 25^{2}, 257,258,264$

Souls, of sinners $12,13,33,74,84$ n.46, 89, $186,246-50,259,262-4$ 
Souls, state of between death and resurrection $5,31-55$

Spanish Islamic communities, social conditions of $270,289,290$

Spanish languages/vernaculars $\quad 270,272$, 273, 274, 291

Spanish Morisco literature 11, 270

Spanish, language $\quad 270,273-5,283,290$ n.83, 291

Sparrow 340

Spies 302, 316

Spinoza 19, 342

Spirits $56,61,64-6,69,70,75,82,127,129$, 323

Spiritual entities, hierarchy of $\quad 56,69$

Spiritual entities, lessening importance of in Islam 70

Srōš 157

Starcky, Jean $\quad 61,62$ n.28

State, use of force by $180-4,185$

Stephen Bar-Sudhaile, East Syrian mystic 61,84 n. 42,189

Stones $13,41,111,127,130,137,15^{2}, 156,157$, 16o, 162, 286, 316, 341

Story-tellers 11, 160 (see also qușșās)

Șubḥī, Aḥmad 212, 214, 217

al-Subkī, Taqī al-Dīn $\quad$ 166, 171-3, 208-11, 219, 220, 223, 228

al-Suddī 118

Suffering $3,16,159,167,186-91,196,197,243$, $251,258,259,263,329$

Sufis/Sufism $\quad 9-10,13,20$ 104, 176, 180, 183, $196,214,321$ n. 65

Suicide 17

Sūkhā'îl, angel 137,138

al-Sulamī 104

Süleimān I, Sulțān 302, 304 n.20

Summer 14, 68, 159

Sun, derives heat from underworld 62

Sunna $178,184,213,224$

Sunni 4, 6, 68, 125 n.3, 141, 175, 176 n.3, 177, $179,184,187,192,208-10,212-6$, 218, 220, 222, 224, 225, 228, 23 n.79, 231 n.82, 241, 242, 300-21, 330, 345

Sunnis, as heretics 307

Sunnis, as idolaters 307

Sunnis, as polytheists 307

Susāīl 139
al-Suyūțī 6, 126 n.7

Swedenborg, Emanuel 190

Sword 181, 302, 311

Sympathy 344

Syria 214

Syriac authors $31,34,36,37,40,41,43,44$, 47, 49, 51

Syriac Christians $\quad 32,34,37,38,43,48-50$

Syriac theologians $41,45,46,48,5^{\circ}$

Țabaqāt $12,13,126,144,149$

al-Ṭabarī 81 n.31, 105 n.9, 115-9, 125 n.3, 151, 159

Tabriz 131, 311, 312, 314, 315, 320, 322, 326, 327 al-Tadhkira fi aḥwāl al-mawtā 85

Tafsìr 129, 134, 136, 146, 151, 159, 171, 177, 305, 316, 317

Ṭahmāsp I, Shāh $\quad 302,304,311,312,313,317$, $318,321,324$

Tacizz 212

The Tale of the Donzella Carcayona 286-8

Tāmir, 'Ārif 244, 245

Tanbīh al-ghäfilin $\quad$ 271, 289

Tanīnā 133, 137

Tartaruchian angels $\quad 88$

Tatirokos, angel 89

Tawba 7 (see also repentance)

Tāwūs 103, 108

Tax-collectors 18

Tayyār 321

Tayyibīs 241, 244, 245 n.10, 26o-2

Teaching of Addai the Apostle 35

Tears 109, 146 (see also weeping)

Teeth $16,87,89,149,153,340$

Tertullian 36 n.16, 48

Tesei, Tommaso $\quad$ 5, 31-55

al-Tha'labī $13,15,119,129-31,134,136,145$

Thawrafil-jahim $336-51$

Theologians $7,8,12,19,20,41,42,45,46,48$, $50,165,173,175,179,183,216,223,233$ n.93, 234 nn.95-7, 235 n.97, 242, 248, 324

Third heaven $\quad 131-3$

Thnetopsychists 45

Tihāma 83, 214

Timothy I, Catholicos $38,42,45,182$ n.34

Timurid 134, 297

Tongue $14,16,17,149,152,153,156,313,316$ 
Torture $15,74,88,90,94,125,145,148,149$, 152-8, 170, 171, 191, 248, 252, 255, 257, 258, 264, 297, 306, 319-21, 343 (see also punishment)

Tottoli, Roberto $\quad 11,124,125,131,159,268-96$ Traditionalist(s) 19, 166, 178, 208, 213-20

Transgressors $168,171,316$

Translation practices $\quad 273-5$

Transmigration of the soul $248,249,251$, $252,253,255,256,257,263,264$ (see also reincarnation and metempsychosis)

Tree of Evil $\quad 84$ n.42

Tree of Knowledge $84 \mathrm{n.42}$

Trees 14, 15, 21, 83, 84, 92, 126, 127, 130, 146, $149,150,153,155,244,313,321,323,341$ (see also Lote Tree and zaqqūm)

Truth 2, 44, 48, 120, 190, 227, 259, 317, 337, 339, 341, 343-6, 349-50

Ṭūsī, Nașīr al-Dīn $\quad 10,19,342$

Uhud, battle of 305

'ulama $\bar{a}^{\prime} \quad 17,146,15^{2}$ (see also religious authorities)

Ultimate Principle 260

'Umar al-Khayyām 175, 342

'Umar II, caliph 268

'Umar, caliph 105, 168, 209, 232 n.90, 301, 304-7, 310

Umayyads $81,158,242$

Ummal-Kitāb 260

Unbelievers $12,90,91,115,116,120,149,166$, 168, 171, 177-9, 193, 198 n.120, 208-11, 215-6, 218, 221-8, 229 n.74, 230 nn.78-9, 231 n.84, 232, 233 n.93, 247, 251, 263, 281, 301, 317, 324

Unbelievers, Reasons for existence of $\quad 224-5$

Unity of God 20, 158, 257

Universal determinism 192

Universalism 20, 165-73, 177-84, 208-37

Universe, as infinitely old 172

Uriah 200

Urination 153,154

Usury $127,130,152,281,282$

'Uthmān, caliph $\quad 146-8,157-8,161,301,302$, 304-7

'Uthmān, excommunication of 306

'Uthmānic codex 306

'Uyūnal-akhbār 104,119
Valleys $\quad 5,12,14,87,111,133,136,139,145$, $149,150,151,276,278,285$ n. 61,287 , 342

Values, ethical $57,196-7,202,345^{-6}, 35^{0}$

Van Leeuwen, Richard $\quad$ 19, 336-51

al-Varāmīnī 318, 320

Vázquez, Miguel Ángel 271

Venus 247,251

Vermin 15

Violence $3,5,83,180,181,186,197,201,202$, 340,342

Voltaire 19, 342

Von Grunebaum, Gustav 3

Vultures 340

Waardenburg, Jacques 62

Wādī Barhūt 12

Wādī Jahannam 12

Wahb b. Munabbih 110, 276, 278

Wakī`b. al-Jarrāh $105 \mathrm{n} .9$

Walāya 301, 306, 310, 311, 328, 330

Walker, Paul 244

Watercress 19 (see also cress)

al-Wayl 150

Weakness, human $\quad 340,344,345$

Weapons, for the revolution in hell 342

Weeping, from fear of hell $89,108-11,119$, $133,152,157,158$

Welch, Alfred $\quad 69,70,93$

West, the $1,2,21,32,165,180,272,336,348$

Whirlwinds 82

Widows $\quad 156$

Wine $17,74,92,94,279,280,281,284,285$ n. $60,286,342$

Winter 14, 159

Wisdom of Solomon, Book of 34

Wives 92, 242, 280, 281, 284

Women, in hell $18,21,127,130,132,153,154$, 159, 279, 28o, 285 n.61, 287, 313

Women's rights 338,341

Worms $153,159,262$

Wounds, fluid of 151,154

Wrath, of God $\quad 8,169-172,185,187-94,226$

Wrongdoers $149,154,155,170,200$

Yahyā b. al-Ḥusayn $\quad 215$

Yājūj and Mājūj 149

Yathrib 172 
al-Yawm al-ākhir 21

Yazīd b. Abān 111

Yazīd b. Marthad 109

Yazīd b. Sharīk 113

al-Yāzij̄i, Ibrāhīm 338

Yça de Segovia 271

Yemen 12, 81 n.31, 131, 135, 212, 214, 215, 218, 219, 228, 241, 260

Young people $\quad 287$

Youths of Ephesus 42

Yūnus b. 'Ubayd 103

Yūsuf al-Qarādāwī $\quad 20,165,208$

Zabāniya $\quad$ 16, 17, 63 74-84, 139, 148, 149 (see also repellers)

Zabāniya, and rabbāniyya $\quad 77-78$

Zabāniya, and the tree of zaqqūm $\quad 83-84$

Zabāniya, as prison-warders 78

Zabāniya, description and origin of $\quad 77-84$
Zabāniya, origins as jinn $\quad 79-81$

Zabāniya, possible Syriac origin of 79

Zabid 131

Zacharias of Mytilene $\quad 42$

al-Zahāwī, Jamīl Șidqī $\quad 19-20,33^{-}{ }^{-1}$

Zähir 10, 20, 242, 243, 245-8, 250, 251, 253, 256,259

al-Zahrawayn 212

al-Zamakhsharī 191

Zamharìr 14, 111, 155, 158, 159, 171, 247

Zamzam 126

Zaqqūm 14, 15, 83, 84, 91, 92, 111, 117, 149, $153-5,321,341$

Zaydān, Jurjī 338

Zaydīs 208, 209, 212-8, 220, 222, 224, 228, 230 n.79, 234 n.96, 241

Zindīq 181, 196, 337 (see also heretics)

Zodiac, sphere of 247,250

Zoroastrianism 180 